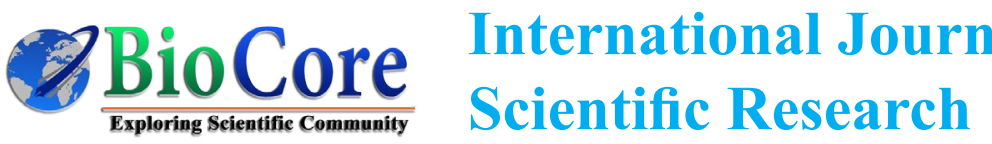

(2)

\begin{abstract}
(2)
\end{abstract}
ISSN 2471-6782

\section{Global Epidemiology of Acute Poisoning with an Emphasis to Ethiopia: Systematic Review}

\author{
Esayas Tadesse G/Mariam*1, Belayneh Kefale Gelaw ${ }^{2}$ \\ ${ }^{1}$ pharmaceutics and social pharmacy unit and Research Team, Department of Pharmacy, College of Medicine and Health Science, Ambo \\ University, Ambo, Ethiopia \\ ${ }^{2}$ Clinical Pharmacy Unit and Research Team, Department of Pharmacy, College of Medicine and Health Science, Ambo University, \\ Ambo, Ethiopia
}

Corresponding author: Esayas Tadesse G/Mariam, pharmaceutics and social pharmacy unit and Research Team, Department of Pharmacy, College of Medicine and Health Science, Ambo University, Ambo, Ethiopia. Email: b.pharm2006@yahoo.com

Citation: Esayas Tadesse G/Mariam et al. (2016), Global Epidemiology of Acute Poisoning with an Emphasis to Ethiopia: Systematic Review. Int J Pharm Sci \& Scient Res. 2:4, 120-130. DOI: 10.25141/2471-6782-2016-4.0161

Copyright: (C2016 Esayas Tadesse G/Mariam et al. This is an open-access article distributed under the terms of the Creative Commons Attribution License, which permits unrestricted use, distribution, and reproduction in any medium, provided the original author and source are credited

Received: August 04, 2016; Accepted: Sepetember 19, 2016; Published: September 29, 2016.

\section{Abstract:}

Introduction: - Acute poisoning is an injury in which the toxic effects occur almost immediately, usually within hours from the time of exposure. It is a common reason for visits to emergency departments and for hospitalization worldwide and its morbidity and mortality is becoming a major public health issue in many countries.

Objective: - To review currently existing literature on the global Epidemiology of Acute Poisoning by giving emphasis to the situation in Ethiopia

Methods: - Pub med, Google, Google scholar, and Medline were searched using subject headings and key words like "Acute poisoning", "epidemiology", "Ethiopia" and those words related to the title of the review.

Findings: - From the review it was found that the epidemiology of acute poisoning varies between countries and different regions. However, the global prevalence of acute poisoning especially in the developed nations reported as decreased. Few epidemiological studies exist in Ethiopia revealed that the greatest proportion of poisonings occurred below 30 years of age and the most frequent circumstance for poisoning was intentional poisoning. Organophosphate pesticide was the most common cause of poisoning. The case fatality rate was reported from $2.4 \%-8.6 \%$

Key words: Acute Poisoning, Epidemiology, Ethiopia, Global.

\section{Introduction:}

\section{Back ground:}

Injury epidemiology is a sub-discipline of epidemiology whose focus is to study the determinants of injuries in the population. It involves the characterizatiaon of injury occurrence, identification of risk factors, and the evaluation of injury prevention and management programs (1). Acute poisoning is an injury in which the toxic effects occur almost immediately, usually within hours from the time of exposure (2). It is a common reason worldwide for visits to emergency departments and for hospitalization and its morbidity and mortality is becoming a major public health issue in many countries. It is estimated that some forms of poisons are directly or indirectly responsible for more than 1 million illnesses worldwide annually (3).

The world health organization (WHO) estimates that the total number of acute unintentional poisonings throughout the world ranges from $2-3$ million cases annually, of which 1 million are severe poisonings resulting in 20000 deaths annually, while the 
estimated annual intentional poisonings number is about 2 million resulting in 200000 suicides $(4,5)$. The exact number of incidences can be higher, because most cases of the poisoning actually go unreported. The problem is getting worse with time as newer drugs and chemicals are developing. Poisoning cases are increasing dayby-day due to changes in the life style and social behavior (6).

Althoughh there are good data bases in developed countries concerning poisoning such as the toxic exposure surveillance system; for most of the low income countries there are no formal and well established poison control centers to collect such data. Hence information on this very important public health issue remains insufficient ( 7$)$.

Substantial differences in socioeconomic and cultural situations in different countries cause various patterns of poisoning with different poisonous agents. The epidemiology of acute poisoning varies between countries and different regions, so epidemiological studies specific for each country and each region is necessary to determine the extent and characteristics of the problem and how this health problem can be prevented (8).

Poisoning by means of hazardous chemicals through ignorance, mishap or intentionally is becoming a serious health problem worldwide. Epidemiological data on this important health issue are, however, scarce in Ethiopia (9).

\section{Statement of the problem:}

Studies have shown that acute poisoning has been identified as a significant global public health problem. According to the WHO, over 350,000 people died worldwide from unintentional poisoning in 2004 resulting in the loss of over 7.4 million years of healthy life (disability adjusted life years (DALYs). Furthermore, nearly a million people die each year as a result of suicide. Although data on the prevalence of poisoning on a global scale may seem to be well established, updated data from developing countries is largely unexplored (10).

A recent report by the American association of Poison Control Centers' National Poison Data System (NPDS) showed that since 2000 , cases with more serious outcomes have increased by $4.6 \%$ from 108, 148 cases in 2000 to 170, 956 cases in 2012 (11). On an African perspective, Malangu (2009) stated that acute poisoning has been identified as a significant cause of both morbidity and mortality, and the hospital prevalence of poisoning has been known to vary up to $17 \%$. In Botswana, poisoning by various agents contributes to $7 \%$ of morbidity and ranks third among injuries leading to hospitalization $(2,3)$.

The epidemiology of poisoning in Ethiopia, as in other African countries, is not well established. It is very difficult to find the primary data of poisoning in the country because most of the screening \& confirmatory tests are not done routinely in the country setup. Additionally, there is no well-organized poison control center in Ethiopia $(9,12)$.

Hence, the researcher was interested to review the epidemiology of Acute poisoning which is useful in the design of interventions directed at the reduction of morbidity and mortality. Due to this scourge, the research question what is the epidemiology of acute poisoning globally and in Ethiopia look likes was formulated.

\section{Objectives}

To review currently existing literature on the global Epidemiology of Acute Poisoning by giving emphasis to the situation in Ethiopia

Methods:

\section{Data sources and searches:}

A systematic search was performed using electronic method. The electronic search was done with Google, Google scholar, Pub med, and Medline. Search strategies used subject headings and key words like "Acute poisoning", "epidemiology", "Ethiopia" and those words related to the title of the review with English as the acceptable language. Reference lists of relevant reviews were also used to identify studies and the cited literature was reviewed.

\section{Study selection:}

The criteria for the study to be included in the review were formulated keeping into account the study objective. Data search used in this review was limited to studies published after 2000. This cut-off was chosen because data collected before 2000 may no longer reflect the current situation of acute poisoning worldwide and in Ethiopia. The majority of articles were retrospective hospitalbased studies in major urban cities that addressed aspects of acute poisoning including incidence, types, risk factors, management, and outcomes while some of these publications included multiple reports from the same studies. Data from abstracts were used if full text of the article could not be acquired. The data sources are mentioned wherever used in the text.

\section{Data extraction and analysis:}

1,260 entries extending from 1966 to 2014 showed using the key words at pub med. We identified 51 studies and from these chosen studies place of study, patterns of acute poisoning in terms of sex, age, types of circumstance and toxic agents, determinants, outcomes and prevention strategies was recorded. For comparison and simplicity of communication the patterns and other epidemiological description was arranged in ascending order, from 2000 to 2015 . There are only two published studies on pub med describing the epidemiology of acute poisoning in Ethiopia. Extrapolations from data published elsewhere have serious limitations. As new and better epidemiological data become available in the country, it will be possible to know the actual burden of acute poisoning in the country.

\section{Findings:}

\section{Acute Poisoning:}

Poison is a substance capable of producing damage or dysfunction in the body by its chemical activity. It can enter the body through various ways and produce general or local effects. Poisoning is a 
qualitative term used to define the potential of a chemical substance in acting adversely or deleteriously on the body (13).

In most cases, the detailed mechanism of poisoning is unknown, but the time between the exposure and the elucidation of the resulting toxic effects determines whether an exposure is acute or chronic. In an acute toxicity or poisoning, the effects occur almost immediately after an exposure. Whether the effects follow a single dose or a series of doses or exposures, when the effects appear within 24 hours, this is termed "acute poisoning" (14). Acute poisoning results from exposures to toxic agents that may lead to harmful effects based on the reaction of the body to these agents. Exposures may be through ingestion, transdermal, injection, or inhalation. The resulting effects of the exposure may be localized, or generalized; they may also be topical or systemic. At the core, the adverse functional or morphological changes observed upon clinical, gross or histopathological examinations are almost invariably a consequence of biochemical lesions (15).

\section{Modes of poisoning:}

Poisoning may occur either intentionally (deliberately) or unintentionally (accidentally). Intentional poisoning is the result of a person taking or giving a substance with the intention of causing harm while unintentional poisoning occurs if a person taking or giving a substance did not mean to cause harm (16).

Unintentional poisoning may result from error in judgment, carelessness, negligence, or an unexpected situation in the home, or at workplace as in the case of intoxication due to treatment, referred to as "iatrogenic intoxication" (17).

In intentional poisoning, the victim is intoxicated on purpose, either by their own doing, this is called "deliberate self-poisoning", it may be para suicide or suicide; or at own request, as in euthanasia, or by being the unwitting victim of intoxication orchestrated with criminal intent (18). When the distinction between intentional and unintentional is unclear, poisonings are usually regarded "undetermined" in intent (16).

It has been shown that consequences of deliberate self-poisoning outweigh those of accidental poisoning by far. WHO estimate that intentional and unintentional injuries constitute about $6.8 \%$ $(770,000)$ of all deaths in low and middle income countries. Poisoning is responsible for about 8.5\% (42,000) of these unintentional deaths due to injuries and self-inflicted injuries is responsible for about $18.3 \%(50,000)$ of the deaths due to intentional injuries $(273,000)(10)$.

\section{Toxic agents used in poisoning}

Poisoning can result from exposure to a variety of substances. The substances used in poisonings vary depending on the area and the culture. Typical agents used in poisonings include, pesticides, rodenticides, herbicides, pharmaceutical products, household chemicals, foods, alcohols, plants, traditional medicines and illegal street drugs (19).

Over the last few decades, agricultural pesticides have become the main source of poisoning in the developing world. Pesticides particularly Organophosphorus compounds are widely used for agriculture, vector control and domestic purposes. Because of their easy availability organophosphorus poisoning has assumed major global health challenge. Pesticide poisoning accounts for about onethird of the world's suicides and deliberate self-poisoning involving these chemicals have been reported in many countries including Ethiopia (2, 3, and 20). Indeed, besides pesticides, other toxic agents such as pharmaceuticals are involved in acute poisoning. Both prescription and non-prescription medicines have been used throughout the world for self-poisoning mainly in urban areas. The most commonly used medicines are central nervous systemacting drugs such as antipsychotics, antidepressants, barbiturates, and benzodiazepines; followed by analgesics mainly paracetamol; anti-epileptic drugs such as carbamazepine; antiseptics and disinfectants; antimalarial drugs such as chloroquine and others (19).

Household products and chemicals, like paraffin, cleaning agents such as bleach and cetrimide, acids and bases used for drain cleaning, shampoos and soaps, disinfectants such as potassium permanganate and creosote; are the most toxic chemicals that can potentially be involved in acute poisoning incidents (19).

Food is another common cause of acute poisoning but due to the lack of effective surveillance systems, its incidence is not well established. Moreover, food poisoning is often confused with food allergy and food adverse effects, which are respectively an immune-mediated reaction, and a clinically abnormal response, attributed to an exposure to a food or food additive $(2,3,20)$. Poisoning from plants is due to their toxic constituents, mainly alkaloids, but also taxanes, glucosides, saponins, flavonoids, and other compounds. Historically plants containing alkaloids such as aconitine, strychnine, and others have been used in criminal poisoning (18).

Moreover, many traditional medicines especially in the tropical regions of Africa contain plants or plant materials that can produce acute poisoning. Snake bite is also a major problem worldwide. It cause considerable death and injury and pose an important yet neglected threat to public health (2.3.20).

\section{Global Epidemiology of Acute Poisoning}

\section{Distribution of acute poisoning}

\section{Magnitude of acute poisoning in terms of prevalence}

The prevalence of acute poisoning in the general population is unknown because of lack of population-based studies. Several studies have reported the prevalence of acute poisoning based on the number of people attending the emergency departments, and / or people admitted in the hospital wards with a diagnosis of acute poisoning. The figures reported vary widely with the size of the denominator used $(2$

World Health Organization estimates that 2 million people attempt suicide and one million accidental poisoning cases occur every year worldwide (5). According to WHO report of Regional distribution of the global poisoning injury burden (DALYs lost), 


\begin{tabular}{|c|c|c|c|}
\hline Country & Year & Study sample & $\begin{array}{c}\text { Prevalence of acute } \\
\text { poisoning }\end{array}$ \\
\hline $\begin{array}{c}\text { Qatar (Khudair eta } \\
\text { al., 2013) }\end{array}$ & 2013 & 599 & $0.035 \%$ \\
\hline $\begin{array}{c}\text { India (Aravind and } \\
\text { Rai, 2014) }\end{array}$ & 2014 & 1324 & $3.55 \%$ \\
\hline $\begin{array}{c}\text { Morocco (Boukatta } \\
\text { et al., 2014) }\end{array}$ & 2014 & 202 & $0.77 \%$ \\
\hline $\begin{array}{c}\text { Kenya Bundotich and } \\
\text { Gichuhi, 2015) }\end{array}$ & 2015 & 96 & $0.07 \%$ \\
\hline
\end{tabular}

Table 1 Prevalence of acute poisoning in hospital based studies in selected countries Pattern of AP in terms of Person, Place, Time \& Toxic agent

the total number of DALYs lost was 8235000 and Europe (28\%) and South-East Asia (28\%) together account for over one-half of the total number of DALYs lost globally to poisoning. While the rest were, in America (5\%), Africa (15\%), west pacific region $(17 \%)$, and middle east region (7\%) (21).

The pattern of acute poisoning changes with time, and differ from country to country, and even between geographical areas within the same country (22). Substantial differences in socioeconomic and cultural situations in different countries also cause various patterns of poisoning with different poisonous agents (19).

Various literatures have shown variations in age and sex distribution of poisoning cases. Males in low and middle income countries of Europe account for the highest number of poisoning worldwide (21). Different retrospective hospital based studies conducted in southern part of India (69.6\%), Iran -Teheran (51\%), Saudi Arabia $(73.6 \%)$ and Kenya have also shown higher incidence of acute poisonings in male $(6,7,23,24)$.

Concerning the distribution age, Over $60 \%$ of the poisoning occurs among adolescents and adults aged between 15-59 years and the majority of cases were in the age range of 21-30 years (21). This was supported by many literatures. For example, a retrospective analysis of acute poisoning conducted in India showed $42.63 \%$ were aged 20-30 years, while in Iran (38\%) of cases were in the age range of 21-30 years. $(6,25)$. Many studies also have revealed that children are particularly at risk for accidental poisoning (26). In a study, which was carried out in Botswana and South Africa, acute poisoning incidents occurred mostly in children younger than 12 years old, then decreased among teenagers, and increased again among young adults, before decreasing among patients over 30 years old $(2,3,20)$.

Seasonal variation of acute poisoning was also seen in studies from different part of the world. In a study conducted in Iran the seasonal distribution in poisoning patients suggested a peak in spring (28\% of presentations) and summer (27.5\%) and lower numbers in winter $(23.6 \%)$ and autumn $(20.8 \%)$. It was also seen that intentional poisoning occurred mostly during spring $(28.2 \%$ of intentional cases), whereas unintentional poisoning was more frequent during autumn (33.3\% of unintentional cases) (27). While in Qatar Seasonal differences were observed with most victims being seen in summer and autumn (28). However, in china there was no significant difference in season distribution. In month distribution, January showed the highest incidence (11.33\%), whereas March had the lowest (6.35\%) (29).

Regarding pattern of poisonous agents among the various causes of poisonings, pesticides are the most common cause of selfpoisoning worldwide, with the proportion ranging from $4 \%$ in the European region to over 50\% in the Western Pacific region (30). A survey conducted in 8 referral hospitals in Zimbabwe revealed that pesticides and pharmaceuticals were the most common toxic agents responsible for hospital admissions (31). In another study conducted in Hong Kong, sleeping pills and analgesics were the most commonly used poisons (32). Sedative hypnotic drugs, opioids and pesticides were common agents in Tehran-Iran (6). In Francistown and Gaborone, Botswana; household chemicals and pharmaceuticals were the predominant cause of acute poisoning (3). In Kampala-Uganda, most of the poisoning cases were due to agrochemicals and household chemicals respectively (20). Medications and pesticides were in descending order the common agents used in Fujian-China (29). In Riyadh-Saudi Arabia, drugs and household chemicals were most prevalent among the cases (26).

Variation also observed on the patterns of the circumstances of poisoning which were intentional, accidental and unknown. Literatures showed that intentional poisoning is the major cause of death in many developing and developed countries. In Turkey overdose and accidental or intentional poisoning has become a problem for emergency care centers (33). 
In India, Morocco, Iran and Kenya $90.2 \%, 85 \%, 79 \%$ \& $48.96 \%$ of Cases were intentional poisonings respectively, while unintentional poisoning has been reported to commonly occur among children $(5,6,7,34)$.

\section{Determinants of Acute Poisoning}

Several factors can contribute to the wide difference in poisoning pattern such as climate (for carbon monoxide poisoning), socioeconomic factors, cultural (traditional remedies versus medical advice and products), ethnic variations and religious beliefs prevalent in the community. In addition, a different prescribing practice between physicians, the type of medications involved and their availability can vary from one country to another (35). There are also many precipitating factors for the occurrence of acute poisoning; Anxiety, depression, isolation, unemployment, failure in examination, marital disharmonies are the common ones (6). It is possible to retain some key risk factors that can lead to defining a "high-risk" group. For acute poisoning, the youth, from teenagers to young adults, particularly those with any psychiatric or psychological disorder, those with history of child abuse, and those who are addicted to any substance, constitute a high-risk group for para- and suicide (36). A systematic review study by Fliege et al. (2009) reported that intentional self-poisoning may occur at all ages, yet adolescents and young adults are at a higher risk. From the same authors, they reported that that there is an association between current self-harm behavior and a history of childhood sexual abuse as well as negative emotions such as anxiety, depression, and aggressiveness (36). While in retrospective hospital study conducted in India, Academic failure and discord within the family or with loved ones were the most commonly cited reasons for suicidal poisoning in the younger age group. Economic hardships and marital discord were important precipitating causes in the middle aged and endogenous depression or the loss of a spouse in the majority of the elderly (25). In Ethiopia other factors reported as associated with intentional poisoning include mental illness and ill health (37).

Many literatures also revealed the mortality/morbidity in any case of acute poisoning depends on a number of factors such as nature of poison, dose consumed, level of available medical facilities and the time interval between intake of poison and arrival at hospital. $(6,23)$

\section{Outcomes of Acute Poisoning}

Unless a short period of medical observation is performed, the management of acute poisoning often requires hospitalization, whose outcomes are the length of stay and the associated costs. If the treatment is successful, the patient would have survived and will be discharged from the hospital. When the treatment is not successful, acute poisoning may lead to death. This outcome is measured as the case fatality rate (2).

Mortality from acute poisoning is a major public health issue in many countries. In developing countries, the mortality related to acute poisoning is very high than developed countries (7). In 2000, an estimated 315000 people worldwide died as a result of unintentional poisoning. Suicide is an important cause of premature mortality, accounting for an estimated mortality, accounting for an estimated 877000 deaths every year $(21,38)$. More than $94 \%$ of fatal poisonings occurred in low- and middle-income countries (21). WHO(2008) reported in its Regional distribution

\begin{tabular}{cccc}
\hline Country & Year & Study sample & $\begin{array}{c}\text { Case fatality of acute } \\
\text { poisoning }\end{array}$ \\
\hline Botswana ((Malangu, 2008b). & 2008 & 116 & $2.6 \%$ \\
China (Chen et al., 2010) & 2010 & 2867 & $0.14 \%$ \\
India (Raizada et al.,2012) & 2012 & 584 & $13.2 \%$ \\
Qatar (Khudair eta al., 2013) & 2013 & 599 & $0.039 \%$ \\
Morocco (Boukatta et al., 2014) & 2014 & 202 & $2.18 \%$ \\
Kenya (Bundotich and Gichuhi, 2015) & 2015 & & $3.13 \%$ \\
\hline
\end{tabular}

Table 2 Case fatality rate of acute poisoning in hospital based studies in selected countries 


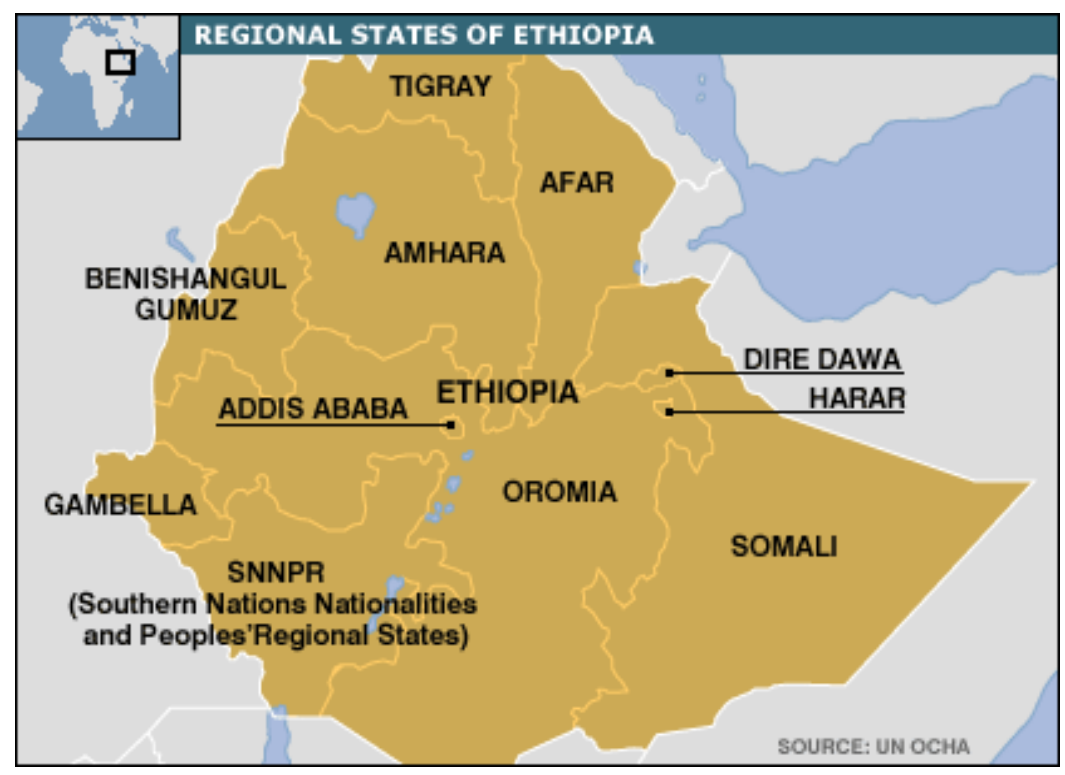

Figure1: Administrative map of Ethiopia

of global poisoning mortality that results in Africa (8\%), America (7\%),Europe(5\%), Eastern Mediterranean region (19\%), south east Asian region (7\%) and in west pacific region (7\%) of the total injury mortality (10).

Many studies also revealed that in developed countries, the rate of mortality from poisoning is $1 \%$ to $2 \%$, but in developing countries the mortality is very high. In India the mortality due to poisoning varies between 15 to $30 \%$ and the poisoning is the fourth most common cause of mortality in rural India $(23,34)$.while in Sri Lanka the reported mortality of $10 \%$ is significantly higher than the $0.5 \%$ reported in high income countries and in the country acute poisoning is among the leading ten causes of hospital death (39). Rates are increasing in USA; the age-adjusted death rate for the United States rose from 4.4 deaths per 100,000 U.S. populations in 1999 to 10.6 deaths in 2010. Unintentional deaths from poisoning comprise the majority of all poisoning deaths. Of the 14,068 poisonings between the years 1999-2012, 78 percent were unintentional, 19 percent were intentional self-inflicted, three percent were of undetermined intent, and less than one percent were intentional assaults (11).

\section{Prevention and control strategies of Acute Poisoning}

Both, preventive and curative interventions are implemented to address and manage the problem of acute poisoning and its victims and in order to reduce the morbidity and mortality, multiple approaches ought to be implemented (2).

Acute poisoning as a health condition deserves to be targeted for preventive interventions. Two public health strategies, namely, individual-centered or 'high risk strategy', and the populationcentered or 'population strategy', need to be operationalized in order to address acute poisoning $(2,3,29)$. High-risk strategy includes managerial decisions at facilities' level such as assessment of poisoning cases with clinical psychometric tools, or referral of deliberate poisoning cases to a psychologist or psychiatrist, specific educational programs for limited households or communities. In this respect, health facilities-based interventions after admission for self-poisoning have become popular in an attempt to reduce repetition and the population strategy includes legislative measures, public educational programs, and establishment of poison or toxicological information centers and services (40). Because serious clinical toxic effects occur in less than $5 \%$ of poisoned patients, identifying patients that require immediate care is paramount to a successful management of victims of acute poisoning. Strategies or treatment options include supportive care, gut decontamination using activated charcoal, increasing drug elimination through multi-dose activated charcoal or urine alkalinisation with sodium bicarbonate, or charcoal hemoperfusion; use of specific antidotes, use of medicines to prevent complications of poisoning, and induction of vomiting where applicable (41).

In addition to these WHO policies aim to reduce death rates by restricting the availability of poisons commonly used for selfharm (21). Different Guidelines put the following key measures as Poison prevention \& control strategies (12).

\section{Epidemiology of Acute Poisoning in Ethiopia}

\section{Country overview}

Ethiopia is a Federal Democratic Republic having 9 nine National Regional States and two city administration and further divided in to 817 districts. Ethiopia is the second largest county among sub-Saharan Africa with the estimated population of more than 85 million of which more than 84 percent live in rural areas. 
The proportion of male and female is almost equal, and around 23.4 percent of women are at reproductive age and 45 percent of the population is at younger age of less than 15 years. Ethiopia is an agrarian country and agriculture accounts for $83.4 \%$ of the labor force, about $43.2 \%$ of the Gross Domestic Product (GDP) and $80 \%$ of exports. The major health problems of the country remain largely preventable communicable diseases and nutritional disorders. Now a day non-communicable disease such as diabetes mellitus, cancers and injuries are amongst the major contributors to the high level of mortality and morbidity in Ethiopia. Despite major progresses have been made to improve the health status of the population in the last one and half decades, Ethiopia's population still face a high rate of morbidity and mortality and the health status remains relatively poor (42)

\section{Epidemiology}

Epidemiological data on acute poisonings in Ethiopia is extremely rare. It is very difficult to find the primary data of poisoning in the country because most of the screening \& confirmatory tests are not done routinely in available set up. Additionally, the country don't have well organized poison control center (12). Furthermore no satisfactory data on demographical and etiological characteristics of poisoning were provided by the annual performance reports and other published documents of ministry of health.

Only few epidemiological studies exist in Ethiopia, concerning acute poisoning and to our knowledge no study on acute poisoning epidemiology in the country has been recently published in an international medical journal. However, these few previously published available evidence suggests that acute poisoning is an important public health problem in Ethiopia.

Pattern of acute adult poisoning at Tikur Anbessa specialized teaching hospital, a retrospective study.

Medical records of 116 adult patients presented to Tikur Anbessa Specialized University Hospital from January 2007 to December 2008 were reviewed retrospectively. Females outnumbered males. Mean age was 21 years. Most (96.5\%) were intentional self-harm poisonings. Household cleansing agents were the leading causes of poisoning (43.1\%) followed by organophosphate $(21.6 \%)$ and phenobarbitone $(10.3 \%)$. Loss of consciousness, vomiting and epigastric pain were the common presenting features accounting $46.2 \%, 23.8 \%$ and $22.5 \%$, respectively. A total of $13(11.2 \%)$ patients had already known mental illness and 12 of them poisoned by using their own medications. Among 65 patients who reported their reason of poisoning, temporary quarrel (57\%) and emotional disturbance $(26 \%)$ were frequently cited. The case fatality rate was $8.6 \%$. Death was most occurred by organophosphate $(5 / 25)$ and phenobarbitone poisoning (3/12). Awareness on proper handling of chemicals and prescribed agents should be forwarded to users of these agents. Majority of patients poisoned for intentional selfharm purposes so that linkage of suicidal patients to appropriate mental health service was recommended. The availability of psychiatry consultation in the hospital was also recommended (37).
The pattern of acute poisoning in a teaching hospital, North-West Ethiopia

The medical records of patients with acute poisonings presented to the Gondar University hospital between July 2001 and June 2004 were reviewed retrospectively. One hundred and two patients presenting to the emergency department of the hospital were due to acute poisoning; accounting for about $0.45 \%$ of emergency room admissions. Organophosphates, rat poison and alcohol were the commonly encountered poisoning agents (in about $70 \%$ of cases) mainly in adults possibly with suicidal or para-suicidal intention. The approaches employed in the management of poisoning mainly involved gastrointestinal decontamination procedures. Specific antidotes were used in a substantial number of patients. The fatality rate was $2.4 \%$. Recording of patient-related information and record-keeping processes should be improved and further large scale studies were required to investigate national trends of poisoning and factors associated with poisoning (9).

Concerning the distribution of acute poisoning in Ethiopia, WHO reported that acute poising accounts $0.5 \%$ of distribution causes of intentional and unintentional injuries in 2012 (43). The weighted pool percentage of seven studies in Ethiopia showed that Organophosphate $(47.2 \%)$ were the leading cause reported. The other reported causes of poisoning were sodium hypochlorite (bleaching agents) $12.9 \%$, Drugs (10\%), Herbicide (6.2\%), Hydrocarbons (2.9\%), Alcohol (2.9\%), carbon monoxide (1.4\%), and in $14.8 \%$ the cause was not identified.(44)

Concerning determinants of poisoning Economic growth, income distribution, geographical difference, education, gender, food and nutrition behavior, lifestyle-related factors, environmental factors related to water and sanitation, waste management, food safety and air quality are some of the major determinants that have direct impact on health outcomes of different socioeconomic groups of a country. Ethiopia recognized the profound effect of the social determinants of health on health and its overall development endeavors (45)

Regarding prevention and control strategies the health sector recognizes that injuries have multiple causes which, with efforts to strengthening the emergency medical services, necessitate multi-sectorial approach towards effective prevention and rapid responses when it occurs (46).

\section{Discussion}

\section{Introduction}

The review sought to describe the Epidemiology of acute poisoning globally as well as in Ethiopia.

\section{Distribution of acute poisoning}

The literature reviewed demonstrates that the alarmingly prevalence and magnitude of acute poisoning and deaths. This is because in the last quarter of the 20th century tremendous advances in the fields of agriculture, industrial technology and medical pharmacy was seen $(6,23)$. Massive use of pesticides in agriculture, 
introduction of a variety of newer drugs for treatment, exposure to hazardous chemical products due to rapid industrialization, unhealthy dietary habits and increase in alcohol consumption have led to a wide spectrum of toxic products to which people are exposed now as compared to the earlier days. These advances have paralleled changes in the trends of acute poisoning in developing and developed countries (47). But the prevalence of acute poisoning in the general population is unknown because of lack of population-based studies. Several reviewed studies have also reported the prevalence of acute poisoning calculated on the basis of all patients that were diagnosed with 'poisoning' or on the basis on a single toxic agent involved in of a confirmed poisoning event. Because the diagnosis is usually based on the patients or relatives reports, with little confirmation by laboratory findings, the accuracy of prevalence figures is limited. There is a further limitation due to the fact that a large portion of patients or those accompanying them are unable to state exactly the nature, type, or the name of the toxic agents involved particularly in case of attempted suicide $(2,3,20)$.

Literatures have also shown variations in age and sex distribution, and toxic agents associated with the morbidity and mortality varies from place to place and over time. This variation has been attributed due to the availability and use of various chemicals and other poisoning agents in different regions; changes in lifestyles, beliefs and traditions of people (19). With regard to gender, there was a great disparity across studies conducted in different countries including Ethiopia. In some studies the majority of the victims were either males or females, while in other studies females and males were affected equally. For this different scholars stated their own justification. For example the prevalence of acute poisonings in males can be due to their more exposure to occupational hazards and stress or strain and also to the fact that females are socially repressed in some culture and do not readily seek medical attention $(6,23,25)$.

Most of the reviewed studies including those from Ethiopia indicated that the prevalence of acute poisoning was high in the age group of 21-30 years. These seem to be in relation with youth characteristics. Supporting this finding, there are reports indicating prevalence of poisoning and death in the young economically active age group (6).

Regarding the types of poisonous agents, it shows geographical variations influenced by economic status. In developed countries, poisoning mostly happens because of drugs, cosmetics and beauty products, household cleansing products and alcohol, while for developing countries like Ethiopia, where the economy is based on agriculture, common causes of poisoning are pesticides, traditional medicines and mushrooms $(8,9)$. Acute organophosphorus pesticides poisoning is widespread in developing countries where there is insufficient regulation, lack of surveillance systems, less enforcement, lack of training, inadequate access to information systems, poorly maintained or non-existent personal protective equipment and larger agriculturally based populations (48).

\section{Determinants of Acute Poisoning}

Besides Accidental poisoning most of the reviewed literatures from the developing countries revealed that the cause of increase in number of self-poisonings is similar for everywhere and may be dependent on factors such as unemployment, urbanization, break up in family support system, failure of love affair and economic instability $(2,6,49)$, while Depression, low self-esteem, and lower social class have been reported as risk factors in developed countries (50). Similarly some literatures including study conducted in Ethiopia mentioned mental illness and psychological problems as risk factors for suicide (37).Patients with intentional poisoning must undergo psychiatric consultation during their stay in the hospital for the treatment poisoning. This will minimize the risk of next attempt of self-harm (16).

\section{Outcomes of Acute Poisoning}

Regarding the outcomes of acute poisonings it comprise an important health issue in developing countries resulting in health threats and hospitalization leading to huge financial burden on victims and an immense strain on hospital services (49). Studies have shown that Intentional poisoning incidents led to the deaths of the victims in many countries including Ethiopia. This is because many literatures state that deliberate poisoning is associated with high mortality because of the ingestion of large quantities of the toxic agents $(2,3,20,37)$. The case fatality rate of developing countries is significantly higher than developed countries. This might be due to the fact that there is strong preventive measures and effective management of acutely poisoned victims in developed countries.

\section{Prevention and control strategies of Acute Poisoning}

Early diagnosis, treatment and prevention are crucial in reducing the burden of poisoning- related injury in any country (39). The WHO identified that a large number of acute poisoning cases can be prevented or lessened through understanding of circumstances, substances and populations at risk coupled with other considerations which may provide pathways to sound policies targeted at poisoning prevention ( 43 ). For example Reports from England and Sri Lanka have shown that legislative measures that restricted access to toxic agents resulted in a decrease in mortality associated with the targeted agents (51). In Ethiopia The health sector recognizes that injuries have multiple causes which, with efforts to strengthening the emergency medical services, necessitate multi sectorial approach towards effective prevention and rapid responses when it occurs (42) however, lot of challenges like Limited mental health service coverage; Lack of technical and financial support; Low level of awareness on non-communicable diseases and their risk factors both in the general population and among health professionals; and Limited number of national and international partners working on non-communicable diseases in the country (45) 


\section{Conclusion}

The literature review has shown that acute poisoning represents a real health problem in the world. The global prevalence of acute poisoning especially in the developed nations reported as decreased but the epidemiology of acute poisoning remains largely unexplored in Ethiopia. The contextual factors of each country led to a pattern of acute poisoning that showed some similarities with regard to the distribution of intentional poisoning among difference age, sex victims. However, there were variations relating to the types of toxic agents in which Organophosphorus pesticides are the most common cause, especially in developing countries whose economic activity is based on agriculture, such as Ethiopia. Multitude of other factors like the country's sociopolitical, economical, and cultural features influence the individual behaviors and circumstances leading to acute poisoning and that the outcomes of acute poisoning vary widely from settings to settings. The mortality rate of acute poisoning in developing countries like Ethiopia is significantly higher than developed countries, where the rate of mortality from poisoning is $1 \%$ to $2 \%$, and the prevention remains the best approach for reducing these morbidity and mortality.

\section{Implications}

Based on the findings of this review a number of important implications stated and it is suggested that multifaceted interventions that tailored to meet the specific realities of the country should be implemented

\section{Public health and policy implications}

- From the finding, organophosphates, household chemicals and prescribed drugs are becoming commonly used agents that cause morbidity and mortality in Ethiopia. So public education programs are necessary to increase the population's awareness of the risks of poisoning at home through designing messages dealing with appropriate storage of products in the home, and explaining what to do in case of a poisoning incident

- Ethiopia is an agrarian country, so pesticide poisoning is increasing more frequently as agrochemical usage of these agents. Therefore implementation of strict legislative measures regarding the sale and distribution of pesticides can reduce the incidence of poisoning in the country .hence the review points out the need for strengthening enforcement of regulations pertaining to the control of, pesticides to prevent unnecessary access and exposure in the general population.

- There is no any poison control center in Ethiopia. Hence practical measures should be implemented in order to start toxicovigilance through the establishment of national or regional poison centers

\section{Implications for clinical practice}

- Data from the literature show that deliberate self-poisoning is prevalent and suicidal behavior seems to result from complications or undiagnosed psychiatric conditions, most commonly mental illness. However Limited mental health service coverage in Ethiopia; mentioned under the major challenges to control non-communicable diseases. So the availability of psychiatry consultation service should be expanded throughout health institutions of the country

Implications for further research

- Epidemiological data on acute poisoning are scarce in Ethiopia. So studies are required to better define the epidemiology/ patterns of acute poisoning incidents and deaths based on the socioeconomic status of the victims; this will assist to identify effective interventions to reduce the harm caused.

\section{List of Acronyms}

DALYs: Disability Adjusted Life Years

NDPS: National Poison Data System

GDP: Gross Domestic Product

OP: Organophosphate

UK: United Kingdom

USA: United States of America

WHO: World Health Organization

\section{Conflict of Interests}

The authors declare that there is no conflict of interests regarding the publication of this paper

\section{Author's Contribution}

ETG has made substantial contributions to conception and gathering of information and has been involved in drafting the manuscript or revising it critically for important intellectual content; and has given final approval of the version to be published. BKG has made substantial contributions to conception and design, or acquisition of data, or analysis and interpretation of data. All Authors read and approved the final manuscript.

\section{Acknowledgement}

The authors are grateful to all health care professionals, researchers and governments working to prevent poisoning related problems. We are also grateful to all the information resources included in this review article.

\section{References}

1. Robertson S (2007). Injury Epidemiology: Research and Control Strategies; 3rd edition. Oxford: Oxford University Press.

2. Malangu N, Ogunbanjo GA (2009). A profile of acute poisoning at selected hospitals in South Africa. South African Journal of Epidemiology Infection, 24:4-16. 
3. Malangu N (2008a). Characteristics of acute poisoning at two referral hospitals in Francistown and Gaborone. SA Fam Pract 50:67.

4. Moazzam M, Al-Saigul AM, Naguib M, Alfi MA (2009). Pattern of acute poisoning in Al-Qassim region: a surveillance report from Saudi Arabia, 1999-2003. East Mediterr Health J 15:1005-10.

5. Banerjee I, Tripathi SK, Sinha Roy A (2012). Clinicoepidemiological characteristics in OP poisoning. North American Journal of Medical Sciences 4:|

6. Shadnia S, Esmaily H, Sasanian G, Pajoumand A, Moghaddam H, Abdollahi M (2007). Pattern of acute poisoning in Tehran-Iran in 2003. Hum Exp Toxicol 26:753-6.

7. Bundotich JK, Gichuhi M (2015). Acute poisoning in the Rift Valley Provincial General Hospital, Nakuru, Kenya: January to June 2012. S Afr Fam Pract 56:1-5.

8. Gheshlaghi F, Reza M, Ardakani P, Yaraghi M, Shafiei F, Behjati M (2013). Acute Poisoning in Children; a Population Study in Isfahan, Iran, 2008-2010. Iran J Pediatr; 23: 189-193.

9. Abula T, Wondmikun Y (2006). The pattern of acute poisoning in a teaching hospital, North West Ethiopia. Ethiop Med J 44: 183-189.

10. World Health Organization (2008). Global Burden of Disease: 2004 update. Geneva: WHO 2008.

11. Mowry B, Spyker A, Cantilena R, Bailey E, Ford M (2013). 2012 Annual Report of the American Association of Poison Control Centers' National Poison Data System (NPDS): 30th Annual Report. Clin Toxicol (Phila) 51:949-1229.

12. Alemu B, Wolde M (2007). Toxicology lecture notes for medical science students. EPHTI, Ethiopia.

13. Kasper H, Braunwal L, Fauci J (2005). Harrison's principles of internal medicine.vol.2. 16th edition. New York: McGraw-Hill Medical Publishing Division.

14. Klassen CD (2008). Toxicology: the basic science of poisons. 7th ed. USA: Mc Graw Hill.

15. Zampagni M, Cascella R, Casamenti F, Grossi C, Evangelisti E, Wright D, etal., (2010). A comparison of the biochemical modifications caused by toxic and nontoxic protein oligomers in cells. J Cell Mol Med. doi: 10.1111/j.1582- 4934.2010.01239.

16. Kaal E, Mori A, Risha P, Hasham S, Mwambete K (2013). A Retrospective Study of Poisoning at Muhimbili National Hospital in Dar-Es' Salaam, Tanzania. Journal of Public Health Frontier 2: 21-26.

17. Hermanns-Clausen M, Weinmann W, Auwärter V, Hentschel R et al (2009). Drug dosing error with drops: severe clinical course of codeine intoxication in twins. Eur J Pediatr 168:819-24.

18. Trestrail H (2007). Criminal poisoning: Investigational guide for law enforcement, toxicologists, forensic scientists, and attorneys. 2nd Edition. Humana Press Inc., New Jersey, USA
19. Eddleston M (2000). Patterns and problems of deliberate selfpoisoning in the developing world. QJM 93:715-31.

20. Malangu N (2008b). Acute poisoning at two hospitals in Kampala-Uganda. Journal of Forensic and Legal Medicine 15: 489-492.

21. World Health Organization (2001). World Health Report 2001. Geneva: WHO, 2001.

22. Lawson R, Craft W, Jackson H (2011). Changing pattern of poisoning in children in Newcastle. Br Med J (Clin Res Ed) $287: 15-7$

23. Unnikrishnan B, Singh B, Rajeev A (2005). Trends of acute poisoning in south Karnataka. Kathmandu University Medical Journal 3:149-154.

24. Abd-Elhaleem Z, Al Muqhem B (2014). Pattern of Acute Poisoning in Al Majmaah Region, Saudi Arabia. American Journal of Clinical and Experimental Medicine 2: 79-85.

25. Raizada A, Kalra P, Khaira A, Yadav A (2012). Profile of hospital admissions following acute poisoning from a major teaching hospital in North India. J Tropical Doctor 42: 70-73.

26. Jepsen F, Ryan M (2005). Poisoning in children. Curr Paediatr 15:563-8.

27. Islambulchilar M, Islambulchilar Z, Kargar-Maher H (2009). Acute adult poisoning cases admitted to a university hospital in Tabriz, Iran. Hum Exp Toxicol, 28: 185-190.

28. Khudair1 I, Jassim Z, Hanssen Y, Alsaad WA (2013). Characteristics and determinants of adult patients with acute poisoning attending the accident and emergency department of a teaching hospital in Qatar. Human and Experimental Toxicology 32:921-929.

29. Chen F, Wen J, Wang X, Lin Q, Lin C (2010). Epidemiology and characteristics of acute poisoning treated at an emergency center. World J Emerg Med 1:154-156.

30. Bertolote JM, Fleischmann A, Butchart A (2006). Suicide, suicide attempts and pesticides: a major hidden public health problem. Bull World Health Organ 84: 260.

31. Tagwireyi D, Ball E, Nhachi F (2002). Poisoning in Zimbabwe: a survey of eight major referral hospitals. J Appl Toxicol 22: 99105.

32. Chan C, Fung T, Lee K, Tsui H, Ngan K, Sy Y, etal (2005). A prospective epidemiological study of acute poisoning in Hong Kong. Hong Kong J emerg. med, 12:156-161.

33. Moghadamnia A, Abdollahi M (2002). An epidemiological study of poisoning in Northern Islamic Republic of Iran. East Mediterr Health J 8:88-94.

34. Boukatta B , El Bouazzaoui A, Guemoune R, Houari N, Sanae A, Sbai H, Kanjaa N (2014). An Epidemiological Study of Adult Acute Poisoning in Fez: Morocco. Clin Toxicol 6: 
35. Hanssens Y, Deleu D, Taqi A(2001). Etiologic and demographic characteristics of poisoning: a prospective hospital-based study in Oman. J Toxicol: Clin Toxicol 39: 371-380.

36. Fliege H, Lee JR, Grimm A, Klapp BF (2009). Risk factors and correlates of deliberate self-harm behavior: a systematic review. J Psychosom. Res 66:477-93.

37. Desalew M, Aklilu A, Amanuel A, Addisu M, Ethiopia $\mathrm{T}$ (2011). Pattern of acute adult poisoning at Tikur Anbessa specialized teaching hospital: A retrospective study in Ethiopia. Hum Exp Toxicol 30:523-27

38. World Health Organization (2003). World Health Report 2003. Geneva: WHO, 2003.

39. ShoaibZaheer M, Aslam M, Gupta V, Sharma V, Khan SA (2009). Profile of poisoning cases at a North Indian Tertiary Care Hospital. HPPI 32: 176-83.

40. Hung HT, Du Nguyen T, Höjer J (2008). The first poison control center in Vietnam: experiences of its initial years. Southeast Asian J Trop Med Public Health 39:310-8.

41. Greene SL, Dargan PI, Jones AL (2005). Acute poisoning: understanding $90 \%$ of cases in a nutshell. Postgrad Med J 81: 20416.

42. Federal Ministry of Health (2014a). Health and Health Related Indicators 2005 E.C (2012/2013). Addis Ababa: Ethiopia

43. World Health Organization (2014). Poisons information, prevention and management. Geneva: WHO, 2014.
44. Azazh A (2010). Case series of 2, 4-D poisoning in Tikur Anbessa Teaching Hospital. Ethiop Med J. 48:243-6.

45. Federal Ministry of Health (2014b). HSDP IV Annual performance Report EFY 2006(2013/14). Addis Ababa: Ethiopia

46. Federal Democratic Republic of Ethiopia Ministry of Health (FMOH) (2010), Health Sector Development Program IV 2010/11 - 2014/15. Addis Ababa, Ethiopia.

47. Flemming k, Van der hoek W, Donald C, Gerard H, Hubert D, Surjit S, Michael E (2003): Reducing Acute Poisoning in Developing Countries- Options for Restricting the Availability of Pesticides.Toxicology 192: 249-261.

48. Thundiyil G, Stober J, Besbelli N, Pronczuk J (2008). Acute pesticide poisoning: a proposed classification tool. Bull World Health Organ 86: 205-9.

49. Aravind A, Rai M (2014). Pattern of Acute Poisoning Admissions in the Medical Intensive Care Unit of a Tertiary Care Hospital. Int. J. Pharm. Sci. Drug Res. July-September 6:239-242

50. Groholt B, Ekeberg O, Wichstrom L, Haldorsen T (2000). Young suicide attempters: a comparison between a clinical and an epidemiological sample. J Am Acad Child Adolesc Psychiatry 39: 868-875.

51. Gunnell D, Eddleston M, Phillips MR, Konradsen F (2007). The global distribution of fatal pesticide self-poisoning: systematic review. BMC Public Health 7:357. 